\title{
A FAVOR, CONTRA, OU ASSIM-ASSIM? POSIÇÕES E DISCURSOS DE MEMBROS DOS ÓRGÃOS DE GESTÃO SOBRE LIMIARES DE REPRESENTAÇÃO LEGALMENTE VINCULATIVOS, MÉRITO E IGUALDADE
}

(iD) Sara Falcão Casaca*
(i) Maria João Guedes**
(i) Susana Ramalho Marques***
(D) Nuno Paço***

\section{Resumo}

Este artigo procura analisar as posições e os discursos de membros dos órgãos de gestão das empresas legalmente vinculadas a limiares mínimos de representação equilibrada entre mulheres e homens. Os resultados mostram que, apesar de não ser expressiva a oposição a medidas vinculativas de ação positiva, a Lei em vigor está longe de ser consensual. As posições de resistência estão mais presentes entre os homens, enquanto são as mulheres que mais contrariam a narrativa de que as medidas vinculativas comprometem a meritocracia. Os discursos das mulheres tendem a negar experiências de discriminação, embora, contraditoriamente, algumas admitam a necessidade de prestar mais provas de competência que os seus colegas. Esta narrativa sugere que as condições em

* Instituto Superior de Economia e Gestão, Universidade de Lisboa; SOCIUS - Centro de Investigação em Sociologia Económica e das Organizações/CSG - Investigação em Ciências Sociais e Gestão - Lisboa, Portugal.

Endereço postal: Instituto Superior de Economia e Gestão, Universidade de Lisboa, Rua do Quelhas, n. ${ }^{\circ}$ 6, 1200-781 Lisboa, Portugal.

Endereço eletrónico: sarafc@iseg.ulisboa.pt

** Instituto Superior de Economia e Gestão, Universidade de Lisboa; SOCIUS - Centro de Investigação em Sociologia Económica e das Organizações/CSG - Investigação em Ciências Sociais e Gestão - Lisboa, Portugal.

Endereço postal: Instituto Superior de Economia e Gestão, Universidade de Lisboa, Rua do Quelhas, n. ${ }^{\circ}$ 6, 1200-781 Lisboa, Portugal.

Endereço eletrónico: mjguedes@iseg.ulisboa.pt

*** SOCIUS - Centro de Investigação em Sociologia Económica e das Organizações/CSG Investigação em Ciências Sociais e Gestão, Lisboa, Portugal.

Endereço postal: SOCIUS / CSG, Rua Miguel Lupi 20, 1249-078 Lisboa, Portugal.

Endereço eletrónico: smarques@iseg.ulisboa.pt

**** SOCIUS - Centro de Investigação em Sociologia Económica e das Organizações/CSG Investigação em Ciências Sociais e Gestão, Lisboa, Portugal.

Endereço postal: SOCIUS / CSG, Rua Miguel Lupi 20, 1249-078 Lisboa, Portugal.

Endereço eletrónico: npaco@iseg.ulisboa.pt 
que exercem cargos de gestão são ainda pautadas pela desigualdade em relação aos pares do sexo masculino.

Palavras-chave: Empresas, ação positiva, mérito, igualdade de género, órgãos de gestão.

\begin{abstract}
For, Against, or Somewhere in the Middle? Positions and discourses of board members about legally binding thresholds of representation, merit and equality

This paper seeks to analyse the positions and discourses of board members serving in companies that are legally bound by a minimum balanced threshold of representation between men and women. The results show that, despite the lack of a marked opposition to legally binding affirmative action measures, the current Law is far from consensual. The greater opposition and resistance is voiced by male board members, while female board members make up the majority of those who contradict the narrative that binding measures may compromise meritocracy. Women tend to deny any experience of discrimination throughout their professional careers, but, contradictorily, they also admit having to provide more proof of competence than their male colleagues. Such a narrative suggests that the conditions in which they serve on boards is still pervaded by inequality in relation to their male peers.
\end{abstract}

Keywords: Companies, affirmative action, merit, gender equality, board members.

\title{
Resumen
}

¿A favor, en contra, o indiferencia? Posiciones y discursos de los miembros de órganos de dirección de las empresas sobre los umbrales de representación jurídicamente vinculantes, merito y igualdad

Este artículo busca analizar las posiciones y discursos de miembros de órganos de dirección de empresas legalmente vinculadas a umbrales de representación equilibrada entre mujeres y hombres. Los resultados muestran que, aunque no existe una expresiva oposición a medidas vinculantes de acción positiva, la legislación vigente está lejos de estar consensuada. Se verifica una mayor resistencia por parte de los hombres, al paso que son fundamentalmente las mujeres que contradicen la narrativa de que las medidas vinculantes amenazan la meritocracia. Los discursos de las mujeres tienden a descartar cualquier experiencia de discriminación en su carrera profesional, pero admitiendo, contradictoriamente, la necesidad de demostrar más competencia que sus homólogos. Esta narrativa sugiere que las condiciones en que las mujeres ejercen los cargos de dirección son marcadas por desigualdades en relación a sus homólogos do sexo masculino.

Palabras clave: Compañías, acción positiva, merito, igualdad de género, órganos de dirección.

\section{Introdução}

A sub-representação de mulheres em cargos de gestão de topo no universo empresarial subsiste de forma transversal em todo o mundo (ILO 2019). A adoção de medidas de ação positiva, por via da definição de limiares mínimos de representação de mulheres e homens nos órgãos de gestão das empresas, tem vindo a ser seguida em vários países europeus (e.g. Mensi-Klarbach e Seierstad 2020). No con- 
texto português, na sequência de infrutíferos incentivos à autorregulação e à adoção voluntária de metas para aumentar a representação de mulheres nos órgãos de administração das empresas cotadas em bolsa (Casaca 2017a; 2017b), entrou em vigor, a 1 de janeiro de 2018, a Lei n. ${ }^{\circ}$ 62/2017, de 1 de agosto, que estabelece o regime da representação equilibrada entre mulheres e homens nos órgãos de administração e de fiscalização das entidades do setor público empresarial (setor empresarial do Estado e setor empresarial local) e das empresas cotadas em bolsa.

Este artigo tem como ponto de partida este recente quadro legislativo. A alusão a «posições e discursos» inspira-se no trabalho prévio de Nogueira (2009), embora este se tenha centrado na análise dos discursos de mulheres em cargos de liderança de vários domínios. Já Santos (2010) analisou as posições de deputadas, deputados e estudantes universitárias/os quanto à Lei da Paridade (aplicável à área política). O presente texto contribui para o enriquecimento da literatura existente, uma vez que não são ainda conhecidos estudos que, em Portugal, tenham aplicado uma abordagem metodológica quantitativa e qualitativa à análise das posições e dos discursos de mulheres e de homens a exercer cargos de gestão nas empresas abrangidas pela referida Lei.

Tendo como referência estudos realizados noutros contextos, esperávamos apreender posicionamentos diversos quanto à adoção de medidas vinculativas de ação positiva, com maior oposição por parte dos homens. Neste caso, a perceção de que essas medidas podem ameaçar e comprometer o status quo dominante tenderia a sustentar uma narrativa assente nos riscos de anulação do mérito e da justiça social. No que se refere às mulheres, além da presença dessa tónica crítica, esperava-se uma maior polarização de posições, incluindo uma narrativa declaradamente apoiante e uma narrativa evolutiva (transição de uma posição de relutância para uma posição favorável), ambas sustentadas no reconhecimento de que a abordagem vinculativa cria oportunidades para a revelação do mérito (e.g. Seierstad 2016). Se o cumprimento estrito dos limiares definidos pela Lei cabe a quem nomeia ou designa os membros dos órgãos de gestão, as posições das mulheres e dos homens que integram esses órgãos afigura-se fundamental para uma melhor compreensão do potencial de efetividade do quadro legal (Benschop e Verloo 2006; Lombardo e Mergaert 2013; Verge e Lombardo 2021).

Os resultados obtidos através da aplicação de um inquérito por questionário e da realização de entrevistas semiestruturadas permitem concluir que, apesar de a maioria dos membros dos órgãos de gestão não se manifestar abertamente contra a adoção de medidas vinculativas de ação positiva, a opção legislativa em curso está longe de ser consensual. É entre os homens que as posições e os discursos se apresentam mais críticos, ao passo que são essencialmente as mulheres quem tende a contrariar a narrativa segundo a qual as medidas vinculativas comprometem a meritocracia, legitimando a ocupação de cargos de gestão de topo com base nas respetivas competências. Não obstante as mulheres entrevistadas ocuparem cargos de poder, as suas narrativas sugerem que as condições em que os exercem 
são ainda pautadas pela desigualdade em relação aos seus pares. Se, por um lado - e à semelhança do estudo prévio de Nogueira (2009) -, os seus discursos tendem a afastar qualquer experiência de discriminação, por outro lado, contraditoriamente, admitem a necessidade de prestar mais provas de trabalho e de competência do que os seus pares do sexo masculino.

\section{Medidas de ação positiva: conceptualização e contextualização}

As medidas de ação positiva (ou ação afirmativa) podem ser descritas como «medidas destinadas a um grupo específico, com as quais se pretende eliminar e prevenir a discriminação ou compensar as desvantagens decorrentes de atitudes, comportamentos e estruturas existentes» (Comissão Europeia 1998, 11). As abordagens subjacentes têm vindo a ser distintas, ora favorecendo incentivos à autorregulação das empresas quanto ao estabelecimento de metas de representação de mulheres e homens nos lugares de gestão e ao respetivo horizonte temporal (opção «ligeira» ou soft), ora determinando a obrigatoriedade legal de cumprimento de limiares mínimos de representação equilibrada (abordagem regulatória vinculativa). Esta última opção tem variado quanto ao grau de «robustez» (hardness) do quadro sancionatório aplicável a situações de incumprimento (Mensi-Klarbach e Seierstad 2020).

A designação de «quotas» na literatura de referência é relativamente comum, sobretudo no quadro dos estudos de origem anglo-saxónica. Esta opção, porém, está longe de ser consensual, sendo mesmo criticada por alguma literatura feminista e por organizações defensoras dos direitos das mulheres. O principal argumento é o de que, enquanto as quotas se aplicam a grupos específicos e minoritários de uma determinada população, as medidas de ação positiva servem o propósito da «paridade» e da efetivação da igualdade substantiva. Estas visam, portanto, a igual representação de ambas as metades da humanidade, mulheres e homens, nos processos de decisão e nas instâncias de poder (Murray, Krook e Opello 2012; Coucello et al. 2016; Lépinard e Rubio-Marín 2018).

A adoção de medidas vinculativas de ação positiva abrangeu, em vários países, primeiramente os cargos de representação política (Holli 2011). Em Portugal, a Lei da Paridade aplicável a esse universo entrou em vigor em 2006, antecipando-se em mais de uma década relativamente à Lei que, desde janeiro de 2018, se aplica aos órgãos de administração e de fiscalização das empresas cotadas em bolsa e do setor público empresarial. Como mais à frente se verá, a centralidade do tema na agenda política foi relativamente tardia e não isenta de resistências por parte da elite empresarial (Espírito-Santo 2018) e de atores políticos com representação parlamentar (Casaca 2017b).

Em 2003, sob a forma de Recomendação, o Comité de Ministros do Conselho da Europa definiu o valor de referência para o limiar mínimo de paridade, esclare- 
cendo que «participação equilibrada de mulheres e homens significa que a representação de cada um dos sexos em qualquer órgão de decisão da vida política ou pública não deve ser inferior a 40\%» (Conselho da Europa 2003, 3). No âmbito da União Europeia (UE), é a partir desse ano que passam a ser disponibilizados indicadores que permitem o acompanhamento, embora superficial, da representação de mulheres e homens na tomada de decisão na esfera empresarial. É na segunda década do seculo XXI que o tema passa a ser explicitamente integrado nas agendas para a igualdade do espaço da UE (Casaca 2017a). Neste contexto, assume relevância a Estratégia para a Igualdade 2010-2015, na qual a «igualdade na tomada de decisão na esfera económica» é inscrita como uma das seis áreas estratégicas. Em 2011, por iniciativa da Vice-Presidente da Comissão Europeia e Comissária para a área da Justiça, Direitos Fundamentais e Cidadania, Viviane Reding, foi lançado um apelo às empresas cotadas em bolsa (Call for self-regulation: Women on the Board, Pledge for Europe) para que voluntariamente estabelecessem metas conducentes a um maior equilíbrio entre mulheres e homens nos conselhos de administração. A esta iniciativa seguiu-se, um ano depois, a apresentação da proposta de Diretiva Europeia, cuja aprovação está ainda suspensa por falta de consenso político.

Não obstante este impasse, estão em vigor medidas vinculativas de ação positiva em sete países: Bélgica, Itália e França (desde 2011), Alemanha (2016), Áustria (2017), Portugal (2018) e Grécia (2020). Este último país, a Espanha e os Países-Baixos já tinham em vigor enquadramentos legislativos ligeiros, desde 2000, 2007 e 2009, respetivamente (EIGE 2020). Os quadros normativos em vigor são, todavia, muito distintos, seja quanto aos limiares de representação, aos segmentos de empresas vinculadas e respetiva expressão no universo empresarial, aos órgãos de gestão e tipos de cargos abrangidos, seja ainda no que se refere aos horizontes temporais de implementação e ao estabelecimento (ou não) de sanções. Também os argumentos adotados têm sido diversos, desde aqueles centrados nos propósitos de aprofundamento da justiça social (minoritários) até aos fundamentos utilitaristas (maioritários) (Humbert, Kelan e Clayton-Hathway 2019; MensiKlarbach e Seierstad 2020).

É de notar que somente a França introduziu a obrigatoriedade de cumprimento do limiar mínimo de paridade (40\%), embora apenas aplicável a cargos não executivos, sendo que a Espanha incorporou essa referência para cargos executivos e não executivos, embora, como já referido, seguindo uma abordagem ligeira e não vinculativa (EIGE 2020). No caso dos demais países, o limiar mínimo tem sido fixado em torno de 33,3\%. Em Portugal, a Lei n. ${ }^{\circ}$ 62/2017, de 1 de agosto, determina a obrigatoriedade de uma representação mínima de 33,3\% do sexo sub-representado nos órgãos de administração e de fiscalização das entidades do setor público empresarial (setor empresarial do Estado e setor empresarial local), a partir de 1 de janeiro de 2018, a cumprir-se para cargos executivos e não executivos. Estabelece, ainda, a obrigatoriedade de uma representação mínima de $20 \%$ do sexo sub-representado nos órgãos de administração e de fiscalização das empresas 
cotadas em bolsa, a partir de 1 de janeiro de 2018, e de 33,3\% após 1 de janeiro de 2020 (requisitos aplicáveis à primeira assembleia geral eletiva e a renovações de mandatos, para o conjunto de cargos executivos e não executivos). Em caso de incumprimento, o quadro sancionatório prevê a aplicação de repreensões com registo público, sanções pecuniárias ou a nulidade do ato de designação. À semelhança do que se verifica noutros países onde está em vigor um quadro normativo vinculativo, também em Portugal a Lei impulsionou o aumento da representação de mulheres nos órgãos de gestão de empresas legalmente vinculadas (Casaca et al. 2021a; 2021b; Casaca, coord., et al. 2021).

\section{Posições e discursos relativamente a medidas de ação positiva: revisão da literatura}

O debate em torno de medidas de ação positiva tem sido perpassado por uma assinalável controvérsia (e.g. Teigen 2000; Dahlerup 2008; Santos e Amâncio 2012a; 2012b; Espírito-Santo 2018). A tónica de oposição tende a ser fundamentalmente exposta pela elite dominante, dada a perceção de potencial ameaça às posições e relações de poder vigentes (Verge e Lombardo 2021). Não surpreende, portanto, que as posições de resistência sejam mais comuns entre os homens que ocupam cargos de poder (Meier 2008; Santos e Amâncio 2010a; 2010b; Murray, Krook e Opello 2012), podendo condicionar ou mesmo minar a legitimidade das medidas vinculativas e o respetivo potencial de efetividade (Verge e Lombardo 2021). Lombardo e Mergaert (2013) conceptualizam a resistência como um fenómeno que emerge durante um processo de mudança, designadamente na fase de implementação de uma determinada política de igualdade de género, em que a oposição dos atores expressa a tentativa de preservação do status quo. À luz desta definição, a resistência exprime-se por via de um discurso adverso relativamente à política em questão, podendo assumir a forma de distanciamento explícito quanto aos objetivos da mesma ou traduzir-se em ações que desafiam a sua efetividade. Seierstad (2016) dá conta de como a resistência de vários homens, no contexto empresarial da Noruega, condicionou o potencial de transformação das relações de poder nos órgãos de gestão, limitando o reconhecimento da legitimidade das mulheres e um igual estatuto relativamente aos seus pares. Essa posição, conclui a autora, "causou dificuldades às mulheres "pioneiras", que precisaram de provar o seu valor num ambiente crítico e muitas vezes hostil» (Seierstad 2016, 396).

Ainda que haja evidência de um maior apoio a este tipo de medidas por parte das mulheres, tradicionalmente excluídas dos círculos de poder, é possível encontrar discursos de rejeição, de aceitação e de ambivalência, sendo que estes podem mudar ao longo do tempo (Teigen 2000; Meier 2008; Sealy 2010; Seierstad 2016; Seierstad et al. 2017). Além disso, vários estudos têm demonstrado que a posição de rejeição, no caso das mulheres, é frequentemente indissociável do receio de 
questionamento das suas competências e da legitimidade para o exercício de cargos de poder, bem como da antecipação do risco de sub-representação e isolamento (Sealy 2010; Simpson, Ross-Smith e Lewis 2010; Kelan e Wratil 2014). A este propósito, a literatura tem também indagado se a mudança descritiva, gerada pela obrigatoriedade de cumprimento de limiares mínimos de representação de cada sexo, potencia a mudança substantiva (Krook e Zetterberg 2014), permite um mínimo de «massa crítica» capaz de superar as desvantagens experienciadas pelas sobreminorias (Santos e Amâncio 2014) - ou tokens (Kanter 1977) -, e se são observadas transformações nas relações de poder intraboard (situação em que mulheres e homens se reconhecem e relacionam em condições de igualdade) (Elstad e Ladegard 2012; Engeli e Mazur 2018).

Alguns estudos têm procurado compreender se, no caso das mulheres, a perceção de barreiras e de desvantagens estruturais em função do sexo favorece uma posição de apoio a medidas vinculativas de ação positiva, ou se, num registo oposto, a ausência dessa perceção sustenta uma posição mais distanciada e crítica em relação às mesmas. A partir de uma análise efetuada aos discursos de mulheres em posições de liderança em diversos contextos, Nogueira (2009) identificou: i) um «discurso essencialista», em que as mulheres negam a vivência de qualquer discriminação, justificando o sucesso alcançado a partir de caraterísticas pessoais muito específicas - competências femininas que as tornam especiais -, embora admitam amiúde que em certos momentos tiveram de trabalhar mais do que os homens para atingir os mesmos objetivos (discurso dominante); e ii) um «discurso de resistência», veiculado por mulheres que assumem ter sido vítimas de discriminação por parte de colegas homens, sublinhando que essa experiência lhes permitiu desenvolver competências para enfrentar outros comportamentos discriminatórios (discurso minoritário).

De entre os argumentos desfavoráveis à implementação de medidas vinculativas de ação positiva sobressai a retórica da meritocracia, que expõe o receio de que tal opção possa comprometer a seleção/nomeação com base no mérito. Santos e Amâncio (2010a; 2010b; 2012a; 2012b), a propósito do estudo sobre os discursos em torno da Lei da Paridade, sublinharam o quanto o mérito é genderizado. De acordo com as autoras, as avaliações tendem a ser enviesadas e «constroem-se em torno das expectativas de menor mérito por parte das mulheres e de legitimidade reconhecida aos homens para ocuparem os cargos de deputados» (Santos e Amâncio 2010a, 49). Além disso, como constatado por Sealy (2010), a partir de entrevistas a administradoras do sector bancário, a noção de meritocracia havia diminuído após terem verificado que o acesso a capital social era mais determinante do que as suas competências profissionais e de gestão. Mais recentemente, Seierstad (2016) identificou a existência de uma «narrativa evolutiva» em entrevistas realizadas a administradoras não executivas. Estas assumiram ter transitado de uma posição de ceticismo em relação a medidas vinculativas de ação positiva, a par de uma forte adesão à retórica da meritocracia, para uma posição firme de 
apoio às mesmas, reconhecendo que permitem a criação de oportunidades de carreira para outras mulheres competentes. Vários estudos têm apoiado esta linha de argumentação, demonstrando que a opção vinculativa não compromete a meritocracia, considerando a elevada qualificação das pessoas eleitas/nomeadas e o seu contributo para a qualidade dos processos de tomada de decisão (e.g. Baltrunaite et al. 2014; Besley et al. 2017).

Além dos argumentos que associam as medidas de ação positiva à desconstrução da dimensão genderizada do mérito, tem sido também enfatizado o contributo das mesmas para uma maior justiça individual e social. As narrativas a favor enfatizam a igualdade de resultados, numa perspetiva mais individual, e/ou apoiam uma visão mais ampla e societal que coloca a tónica na reparação das desvantagens estruturais baseadas no sexo (e.g. Dahlerup 2008; Lépinard e RubioMarín 2018). No entanto, a retórica da (in)justiça é também utilizada por narrativas oponentes, segundo as quais a escolha deve recair sobre a pessoa mais qualificada, independentemente do sexo, sob pena de se incorrer numa discriminação inversa e/ou de se violar o princípio do mérito (Dahlerup 2008; Kelan e Wratil 2014). Uma outra narrativa, seguindo uma argumentação utilitarista (business case), coloca a tónica nos benefícios da diversidade, sustentando que a complementaridade entre características femininas e masculinas conduz a melhores resultados financeiros e económicos, tanto a nível organizacional como para as economias e as sociedades em geral (Simpson, Ross-Smith e Lewis 2010; Terjesen e Sealy 2016; Huse 2018).

\section{Análise e discussão dos resultados}

\section{Opções metodológicas e descrição dos/as participantes}

O estudo apoiou-se numa abordagem metodológica mista, que combinou o método quantitativo com o qualitativo em diferentes momentos da investigação. Esta opção decorreu, numa primeira fase, do propósito de desenvolver uma análise descritiva e abrangente que permitisse comparar as posições de mulheres e de homens - membros dos órgãos de gestão das empresas legalmente vinculadas quanto a medidas de ação positiva e ao quadro legal vigente em particular. Num momento seguinte, e num plano complementar, empreendeu-se uma análise interpretativa dessas posições e das narrativas que as sustentam, assim como das eventuais ambivalências e contradições discursivas. Procurou-se ainda compreender se, segundo as perceções das pessoas inquiridas e entrevistadas, o facto de serem mulheres ou de serem homens influiu nos respetivos percursos profissionais.

No primeiro trimestre de 2019, foram contactadas todas as empresas cotadas em bolsa e do setor público empresarial para recolha do endereço de email do secretariado da administração. Terminado o respetivo processo de recolha, foi dis- 
tribuído pela lista de endereços um documento com informação sobre o Projeto ${ }^{1}$, o convite para que membros dos órgãos de administração e de fiscalização preenchessem um inquérito por questionário (online) e participassem numa entrevista futura. Na sequência deste contacto, foi distribuído um inquérito por questionário a 230 membros $(\mathrm{M}=87$ e $\mathrm{H}=143)$. Obteve-se um total de 161 respostas válidas $(\mathrm{M}=84$ e $\mathrm{H}=77)$, tendo-se salvaguardado o anonimato das pessoas participantes. Considerando os universos totais de membros efetivos nos anos em que o questionário foi aplicado, as respostas representam, aproximadamente, $9 \%$ de membros do universo das empresas cotadas em bolsa e $10 \%$ no caso das entidades do setor público empresarial. No que diz respeito à idade das pessoas inquiridas, esta situava-se entre os 30 e os 81 anos (média=52 anos), sendo, em média, os homens mais velhos do que as mulheres ( 54 anos e 50 anos, respetivamente).

Foram ainda realizadas 43 entrevistas semiestruturadas $(\mathrm{M}=22$ e $\mathrm{H}=21)$, entre novembro de 2019 e novembro de 2020. A idade das pessoas entrevistadas situava-se entre os 33 e os 69 anos (média=52 anos), sendo a idade média das mulheres de 50 anos (intervalo etário 38-61 anos) e a dos homens de 54 anos (intervalo etário 33-69 anos).

As entrevistas foram integralmente transcritas e anonimizadas com recurso à atribuição de um código a cada pessoa entrevistada ${ }^{2}$. O conteúdo foi sujeito a análise de conteúdo, com recurso ao software MAXQDA 2020, da qual resultou a identificação de um conjunto de dimensões temáticas transversais ao discurso das pessoas entrevistadas, cada uma das quais desagregada por subtemas. A apresentação dos resultados está organizada em torno de três domínios: (i) limiares vinculativos de representação equilibrada entre mulheres e homens nos cargos de gestão, (ii) medidas de ação positiva e a questão do mérito, e (iii) igualdade de oportunidades ou experiência de discriminação no percurso profissional.

1 «Women on Boards: An Integrative Approach / Mulheres nos Órgãos de Gestão das Empresas: Uma Abordagem Integrada» (PTDC/SOC-ASO/29895/2017), financiado pela Fundação para a Ciência e Tecnologia e pelo Ministério da Ciência, Tecnologia e Ensino Superior (MCTES), através de fundos nacionais (PIDDAC), e desenvolvido no âmbito do Centro de Investigação em Sociologia Económica e das Organizações (SOCIUS)/Consórcio em Ciências Sociais e Gestão (CSG), do ISEG-ULisboa.

2 A anonimização das entrevistas foi efetuada de acordo com o seguinte racional: a primeira letra corresponde ao sexo da pessoa entrevistada $(\mathrm{M}=$ Mulher $/ \mathrm{H}=$ Homem), seguida de um conjunto de três letras que correspondem ao universo da empresa de referência (Cot = Empresa cotada em bolsa $/$ See = Empresa do setor empresarial do Estado/Sel = Empresa do setor empresarial local), e terminando com um ou dois algarismos, que representam o número da entrevista (por ordem cronológica de realização). 
Limiares vinculativos de representação equilibrada entre mulheres e homens nos cargos de gestão: a favor, contra, ou assim-assim?

Cerca de metade das pessoas inquiridas - mais as mulheres (50\%) do que os homens (40,8\%) - manifestou-se a favor de medidas voluntárias de autorregulação que permitam uma representação equilibrada entre mulheres e homens nos órgãos de gestão. É manifestamente inferior a proporção de respostas a favor de medidas vinculativas de ação positiva (33,3\% das mulheres e 27,6\% dos homens) (Anexos, Quadro 1). A proporção de homens que se exprimiu contra quaisquer medidas de representação equilibrada duplica a de mulheres (30,3\% e 14,3\%, respetivamente), embora a diferença não seja estatisticamente significativa $(p>0,05)$. Na mesma linha, quando inquiridos/as especificamente sobre a Lei em vigor, as mulheres manifestaram uma maior concordância com a mesma, sendo as diferenças estatisticamente significativas $(p<0,05)$. Este sentido de respostas é confirmado pelas entrevistas; neste caso, as perspetivas relativamente ao novo quadro legal repartiram-se entre um posicionamento favorável (sem reservas ou com mudança ao longo do tempo [narrativa evolutiva]) e a ambivalência (com argumentos tanto a favor como contra), com uma minoria de pessoas a manifestarem discordância. Os exemplos seguintes são ilustrativos destas posições:

Eu sou a favor na medida em que a Lei pode acelerar, digamos assim, este processo de integração das mulheres. E se as mulheres ... colocarem a jogo todas as suas competências e, entre aspas, brilharem, depois, nesses sítios, não tenho a menor dúvida que a Lei, aí, ajudou a que esta evolução e esta paridade fosse mais cedo. (H_Sel33)

Hoje em dia sou uma adepta das quotas, [...], mas aqui há uns tempos atrás achava que não, que as pessoas tinham que chegar lá só pelo mérito. A verdade é que, à medida que a minha carreira foi evoluindo, eu também comecei a chegar à conclusão que há tantos homens que chegam aos lugares sem nenhum mérito, que nós também merecemos chegar lá por outras razões. (M_See7)

No que se refere à posição ambivalente, com argumentos tanto a favor como contra a Lei, esta assentou sobretudo numa narrativa que descreve as medidas vinculativas de ação positiva como um mal necessário. Os exemplos seguintes são ilustrativos desta perspetiva:

Acho que foi um mal necessário. Por um lado, pode abrir aqui um bocadinho aquela desculpa do «só está porque há as quotas», mas não, mas claramente foi uma porta que teve de se obrigar a abrir, e depois cabe a cada mulher, assim como cabe a cada homem, entrar e fazer o seu caminho. Mas veio acelerar a diversidade, e acelerar este processo, acho que faz todo o sentido. (M_See13)

Se me perguntar diretamente se eu acho que tem que existir legislação a impor, eu acho que infelizmente tem. Eu não sou muito fã, diria, de haver uma legislação que 
obrigue, porque eu acho que isso devia ser consensual e natural, em função das aspirações das pessoas aos cargos, e em função da capacidade que as pessoas têm para os exercer, e não porque é homem, ou porque é mulher. (M_See18)

\section{Medidas de ação positiva e a questão do mérito...}

Verificou-se entre as pessoas inquiridas uma manifesta concordância ( 1 =Discordo Totalmente a $5=$ Concordo Totalmente) com a declaração «As mulheres que estão a ser nomeadas para os cargos nos órgãos de administração têm as competências necessárias para assumir esses cargos» $(\mathrm{M}=4,16 ; \mathrm{H}=3,92)$. Houve, no entanto, uma menor concordância relativamente à afirmação «Deve ser o Estado, sob a forma de leis ou similares, e não os/as acionistas, a decidir quem devem ser os membros do órgão de administração» $(\mathrm{M}=2,29 ; \mathrm{H}=2,05)$ (Anexos, Quadro 2).

Da análise a um conjunto de afirmações relacionadas com a competência das mulheres, as que obtiveram mais concordância foram «Existem mulheres competentes em número suficiente para assumir os cargos executivos» $(\mathrm{M}=4,63 ; \mathrm{H}=4,26)$ e «Existem mulheres competentes em número suficiente para assumir os cargos nos órgãos de administração» $(\mathrm{M}=4,61$ e 4,28). As diferenças entre as respostas das mulheres e dos homens são estatisticamente significativas $(p<0,01$ e $p<0,02$, respetivamente) (Anexos, Quadro 2).

Apenas uma minoria de pessoas entrevistadas, cerca de cinco, exprimiu abertamente uma posição desfavorável em relação à Lei, com uma argumentação sobretudo assente na retórica da meritocracia - tal como exemplificado pelos seguintes depoimentos:

Eu sou contra a Lei das quotas, tudo quanto seja obrigatório, a mim arrepia-me um bocadinho, até porque nós, mulheres, na minha opinião, nunca nos devemos afirmar pelo sexo, ou pelo género, como quisermos, mas sim por aquilo que temos capacidade para fazer. (M_Sel22)

Em conversa com uma amiga minha sobre estas questões, a opinião dela é contrária à minha, ela é favor da Lei da Paridade e eu sou do mérito. (H_See27)

São essencialmente as mulheres quem considera que as medidas vinculativas de ação positiva não põem em causa o mérito, enquanto os homens são quem mais refere que a Lei pode violar esse princípio:

Acho que há muitos homens com pouco mérito nos Conselhos de Administração. (M_Cot_15)

Não é por terem que escolher uma mulher que vão escolher uma incompetente porque têm muitas mulheres competentes, até diria que têm mais mulheres competentes do que homens competentes. (M_See28) 
Custa-me um bocadinho nós subvertermos o princípio da competência por via do princípio da quota, ou seja, eu sinto-me violentado se eu tiver que deixar uma pessoa competente de fora para colocar uma pessoa incompetente para cumprir uma quota, sinto-me violentado. Mas também sinto, e este é um sentimento contraditório, eu sei que se não forçarmos, a transformação depois também não se faz. (H_Sel21)

É de salientar a existência de discursos contraditórios por parte de algumas pessoas entrevistadas, que, apesar de se manifestaram contra limiares vinculativos de representação equilibrada entre mulheres e homens para os órgãos de gestão, rejeitam que essa obrigação possa comprometer a meritocracia. O contrário também pôde ser observado: discursos aparentemente favoráveis à existência de limiares vinculativos e que, simultaneamente, exprimiram o receio de que o mérito possa ser posto em causa. Os seguintes excertos ilustram esses casos:

Não acho [...] que é por força de uma Lei que as mulheres têm de estar lá, as mulheres têm de estar lá pela competência, por aquilo que valem e por aquilo que sabem fazer. [...] Como eu tenho muita confiança no mérito das mulheres em geral, nunca seria posto em causa o mérito [com a introdução da Lei], porque se trata de fazer ascender uma mulher que se calhar por outra via não chegaria lá. (M_Se19)

Por mim [a Lei] parece-me bem. [...] Eu penso que a questão da paridade é, obviamente, muito importante, mas eu acho que a paridade não pode deixar de ser acompanhada com competência, ou seja, porque senão corremos o risco de ter efeitos perversos relativamente a isso, ou seja, começarmos a ter empresas, pessoas, só porque são de um sexo ou de outro, têm de estar lá de qualquer maneira, e que depois não acrescentam nada. (H_See19)

Igualdade de oportunidades e ausência de discriminação, mas...

Parece haver uma perceção generalizada, entre as pessoas inquiridas, de que o percurso profissional foi pontuado pela igualdade de oportunidades; assim, a ampla maioria considera que teria tido as mesmas oportunidades de progressão na carreira caso fosse do sexo oposto, sendo a tendência de resposta semelhante para homens e mulheres (77,9\% e 80,7\%, respetivamente) (Anexos, Quadro 1). Também a maioria das pessoas entrevistadas referiu que o facto de serem mulheres ou de serem homens não condicionou nem facilitou os respetivos percursos profissionais. Dada a sub-representação de mulheres em órgãos de gestão, procurou-se aprofundar o sentido dos discursos das entrevistadas, nem sempre isentos de contradições. Se no decurso da entrevista algumas afirmaram nunca se terem sentido limitadas/discriminadas nas suas aspirações e percursos profissionais, houve momentos em que admitiram a necessidade de dar mais provas de trabalho e de competência que os seus pares do sexo masculino (realidade igualmente reco- 
nhecida pelos homens quanto às colegas administradoras). Os seguintes excertos constituem exemplos destes registos contraditórios:

O facto de ser mulher não me impede de seguir os meus sonhos, ou as oportunidades que me surgem na vida [...]. Eu tenho que me esforçar muito mais para mostrar aquilo que eu penso, e as ideias que eu tenho, e que gostava de implementar, ou a minha opinião sobre determinados aspetos [...]. Eu tenho que me esforçar muito mais para fazer levar a minha opinião, para a levarem a sério, e até perceberem, para a considerarem. (M_Sel10)

Eu sempre pensei, e continuo a pensar, que pelo facto de ser mulher tenho os mesmos direitos, as mesmas aspirações [...] que [outra pessoa] qualquer, seja homem ou mulher [...]. Eu acho também que nós mulheres temos sempre que provar mais [...], temos que apresentar mais trabalho, para convencer as pessoas, porque infelizmente ainda há muita gente que acha que as mulheres não têm as mesmas capacidades de chefia que os homens, ainda está muito enraizado também na sociedade. (M_See_24)

As mulheres têm que mostrar muito mais que são merecedoras de determinados cargos. Não devia ser assim, não é? [...] Continuo a achar e falando com outras mulheres dirigentes, sinto que elas fazem um esforço muito maior no sentido de estar permanentemente a mostrar que merecem aquele lugar. (M_Sel29)

\section{Conclusões e considerações finais}

Este artigo teve como ponto de partida o recente quadro legislativo que determina limiares mínimos de representação equilibrada entre mulheres e homens nos órgãos de gestão das empresas cotadas em bolsa e do setor público empresarial, analisando as posições e os discursos de membros daqueles órgãos quanto aos seguintes domínios: limiares vinculativos de representação equilibrada, medidas de ação positiva e a questão do mérito, e a experiência de igualdade ou de discriminação no percurso profissional.

Quanto aos primeiro e segundo domínios em análise, constatou-se que apenas um terço das mulheres e um pouco mais de um quarto dos homens inquiridos se manifestaram a favor de medidas vinculativas de ação positiva. À semelhança do verificado noutros estudos, são os homens quem mais se exprime contra uma opção vinculativa (Meier 2008; Santos e Amâncio 2010a; 2010b; Murray, Krook e Opello 2012). No caso das entrevistas em profundidade, o mesmo sentido de respostas pôde ser confirmado. As perspetivas relativamente ao novo quadro legal repartiram-se entre uma posição favorável (sem reservas ou com mudança de posição [narrativa evolutiva]) e ambivalente (com argumentos tanto a favor como contra), com uma minoria a manifestar a sua discordância relativamente ao mesmo. Neste último caso, os argumentos veiculados associaram-no a um «mal 
necessário»ou, como identificado noutro estudo, a uma «estratégia imperfeita num mundo imperfeito» (Seierstad 2016, 397).

Entre as pessoas que consideraram que as medidas vinculativas de ação positiva não põem em causa a meritocracia, as mulheres estavam em maioria, justificando a sua posição com base na competência das próprias e das administradoras suas conhecidas. Como esperado, foram essencialmente os homens a expor uma narrativa crítica e uma linha de argumentação contrária. Tanto no caso das mulheres como no dos homens, as reservas relativamente a esta questão assentaram em argumentos de (in)justiça/violação do princípio do mérito (Dahlerup 2008; Santos e Amâncio 2010a; Baltrunaite et al. 2014; Kelan e Wratil 2014; Seierstad 2016; Besley et al. 2017).

Relativamente ao terceiro tema (experiência de igualdade ou de discriminação no percurso profissional), os resultados dão conta de uma perceção generalizada - tanto no caso dos homens como no das mulheres - de terem beneficiado de igualdade de oportunidades. Os discursos das mulheres, a este respeito, consolidam uma narrativa de ausência de discriminação ou de limitações impostas às suas aspirações e percursos profissionais. À imagem do concluído por Nogueira (2009), registámos discursos contraditórios por parte de algumas mulheres, que tanto afirmaram nunca se terem sentido limitadas/discriminadas, como admitiram a necessidade de prestar mais provas de trabalho e de competência que os seus colegas. Esta constatação sugere que, não obstante ocuparem cargos de poder, as condições em que os exercem são ainda pautadas pela desigualdade em relação aos pares do sexo masculino.

Importa notar que cerca de um quinto das pessoas inquiridas $(30,3 \%$ no caso dos homens) manifestou-se contra quaisquer medidas tendentes a promover uma representação equilibrada entre mulheres e homens nos órgãos de gestão. Embora o cumprimento estrito dos limiares definidos pela Lei seja responsabilidade de quem nomeia ou designa os membros dos órgãos de gestão - acionistas ou membros do governo -, as pessoas inquiridas fazem parte de um grupo de atores-chave na transformação do status quo dominante e na efetivação da igualdade substantiva (objetivo subjacente à adoção de medidas de ação positiva). Enquanto posições críticas e de oposição dificilmente podem sustentar dinâmicas de interação favoráveis à igualdade entre mulheres e homens nos órgãos de gestão, já o reconhecimento do quadro legal enquanto oportunidade de superação de desvantagens estruturais em função do sexo pode indiciar a predisposição para a partilha efetiva do poder empresarial e económico. Nesse sentido, os resultados obtidos alertam para a necessidade de uma estratégia política integrada que potencie o respetivo alinhamento de todos os atores relevantes. Esta estratégia deve contemplar programas de sensibilização e de capacitação em torno das causas das assimetrias entre mulheres e homens em cargos de poder, visando a eliminação de estereótipos de género e a igualdade efetiva entre mulheres e homens nas organizações. Neste âmbito, afigura-se igualmente importante a ampla disseminação de infor- 
mação sobre os perfis de mulheres e homens em cargos de poder, favorecendo a desconstrução da retórica da meritocracia (Lombardo e Mergaert 2013; Verge e Lombardo 2021).

São várias as linhas de investigação que ficam por prosseguir. Uma delas prende-se com a análise dos efeitos da mudança descritiva suscitada pela Lei - refletida numa aceleração na representação de mulheres nos órgãos de gestão das empresas legalmente vinculadas - na representação substantiva (Krook e Zetterberg 2014). A este respeito, os resultados alcançados suscitam várias questões: em que medida um maior equilíbrio nos órgãos de gestão conduzirá a uma maior integração de temas relativos à promoção da igualdade entre mulheres e homens nas respetivas empresas? Que repercussões terá a determinação de limiares mínimos de representação de cada sexo no perfil de membros que integram os órgãos de gestão e nos circuitos de poder? Este artigo oferece um dos olhares analíticos possíveis, num terreno que se afigura fértil e aberto a várias outras investigações futuras.

\section{Referências bibliográficas}

Baltrunaite, Audinga, Piera Bello, Alessandra Casarico, e Paola Profeta. 2014. «Gender quotas and the quality of politicians.» Journal of Public Economics 118: 62-74. DOI: https:/ / doi. org/10.1016/j.jpubeco.2014.06.008

Benschop, Yvonne, e Mieke Verloo. 2006. «Sisyphus' Sisters: Can Gender Mainstreaming Escape the Genderedness of Organizations?» Journal of Gender Studies 15(1): 19-33. DOI: https:/ / doi.org/10.1080/09589230500486884

Besley, Timothy, Olle Folke, Torsten Persson, e Johanna Rickne. 2017. «Gender Quotas and the Crisis of the Mediocre Man: Theory and Evidence from Sweden.» American Economic Review 107(8): 2204-2242. DOI: https:/ / doi.org/10.1257/ aer.20160080

Casaca, Sara Falcão. 2017a. «A igualdade entre mulheres e homens e a tomada de decisão na esfera económica: o longo percurso dos instrumentos normativos.» Revista do Centro de Estudos Judiciais 1: 173-199.

Casaca, Sara Falcão. 2017b. «Portugal: The Slow Progress of the Regulatory Framework.» In Gender Diversity in the Boardroom. Volume 2: Multiple Approaches Beyond Quotas, editado por Cathrine Seierstad, Patricia Gabaldon, e Heike Mensi-Klarbach, 45-75. Londres: Palgrave Macmillan.

Casaca, Sara Falcão, Maria João Guedes, Susana Ramalho Marques, e Nuno Paço. 2021a. «WoBómetro.» Disponível no endereço https://womenonboards.pt/wobometro/ [Consultado em 2 de maio de 2021].

Casaca, Sara Falcão, Maria João Guedes, Susana Ramalho Marques, e Nuno Paço. 2021b. «Is a progressive law accelerating the longstanding snail's pace? Women on corporate boards in Portugal.» Revista de Administração de Empresas 61(2): 1-7. DOI: https:/ / doi. org/10.1590/S0034-759020210206

Casaca, Sara Falcão (coord.), Maria João Guedes, Susana Ramalho Marques, Nuno Paço, e Heloísa Perista. 2021. Equilibrio entre Mulheres e Homens nos Órgãos de Gestão das Empresas - Livro Branco. Lisboa: SOCIUS [no prelo]. 
Comissão Europeia - Direcção-Geral do Emprego, Relações Laborais e Assuntos Sociais. 1998. A igualdade em 100 palavras - Glossário de termos sobre igualdade entre homens e mulheres. Luxemburgo: Serviço das Publicações Oficiais das Comunidades Europeias. Disponível no endereço https: / / op.europa.eu/pt/publication-detail/- / publication/ 7342d801-86cc-4f59-a71a-2ff7c0e04123 [Consultado em 28 de junho de 2021].

Conselho da Europa. 2003. «Recomendação Rec (2003) 3 do Comité de Ministros aos Estados Membros sobre participação equilibrada de mulheres e homens na tomada de decisão política e pública (adoptada pelo Comité de Ministros a 12 de Março de 2003).» Disponível no endereço https:/ / rm.coe.int/CoERMPublicCommonSearchServices / DisplayDCTMContent?documentId=0900001680591601 [consultado em 20 de maio de 2021].

Coucello, Ana, Maria do Céu Cunha Rêgo, Maria Alzira Lemos, Margarida Marcelino Marques, Maria Reynolds de Sousa, Maria Regina Tavares da Silva, e José Gabriel Trindade Santos. 2016. «Afinal, o que é a Democracia Paritária? A participação de mulheres e homens na organização social.» Lisboa: Plataforma Portuguesa para os Direitos das Mulheres (Projecto Capacita). Disponível no endereço http:/ / plataformamulhe res.org.pt / site / wp-content / ficheiros / 2016 / 04 / PpDM-Argumentario-afinal-o-quee-a-democracia-paritaria.pdf [Consultado em 28 de junho de 2021].

Dahlerup, Drude. 2008. «Gender Quotas: Controversial but Trendy.» International Feminist Journal of Politics 10(3): 322-328. DOI: https: / / doi.org/10.1080/14616740802185643

EIGE-European Institute for Gender Equality. 2020. Beijing + 25: The Fifth Review of the Implementation of the Beijing Platform for Action in the EU Member States. Luxemburgo: Publications Office of the European Union. Disponível no endereço https://eige. europa.eu/publications / beijing-25-fifth-review-implementation-beijing-platform-action-eu-member-states [Consultado em 14 de junho de 2021].

Elstad, Beate, e Gro Ladegard. 2012. «Women on corporate boards: key influencers or tokens?», Journal of Management and Governance 16: 595-615. DOI: https:/ / doi.org/ 10.1007/ s10997-010-9165-y

Engeli, Isabelle, e Amy Mazur. 2018. «Taking implementation seriously in assessing success: The politics of gender equality policy.» European Journal of Politics and Gender 1(1-2): 111-129. DOI: https: / / doi.org/10.1332/251510818X15282097548558

Espírito-Santo, Ana. 2018. «From Electoral to Corporate Board Quotas: The Case of Portugal.» In Transforming Gender Citizenship, editado por Éléonore Lépinard, e Ruth Rubio-Marín, 216-244. Cambridge, U.K.: Cambridge University Press. DOI: https:/ / doi. org / 10.1017/9781108636797.008

Holli, Anne Maria. 2011. «Transforming Local Politics? The Impact of Gender Quotas in Finland.» In Women and Representation in Local Government, editado por Barbara Pini, e Paula McDonald, 142-158. London \& New York: Routledge.

Humbert, Anne Laure, Elisabeth K. Kelan, e Kate Clayton-Hathway. 2019. «A rights-based approach to board quotas and how hard sanctions work for gender equality.» European Journal of Women's Studies 26(4): 447-68. DOI: https:// doi.org/10.1177/135050681 9857125

Huse, Morten. 2018. «The Business Utility Case for Women on Boards: Going Beyond the Surface.» In More Women on Boards: An International Perspective, editado por Lynne E. Devnew, Marlene Janzen Le Ber, Mariateresa Torchia, e Ronald J. Burke, 17-34. Charlotte, NC: Information Age Publishing.

ILO - International Labour Organization. 2019. A Quantum Leap for Gender Equality: For a Better Future of Work for All. Geneva: ILO. Disponível no endereço https: / / www.ilo. 
org/wcmsp5 / groups / public/---dgreports /---dcomm/---publ/ documents / publica tion/wcms_674831.pdf [Consultado em 3 de maio de 2021].

Kanter, Rosabeth Moss. 1977. «Some Effects of Proportions on Group Life: Skewed Sex Ratios and Responses to Token Women.» American Journal of Sociology 82(5): 965-990. DOI: https:/ / doi.org/10.1086/226425

Kelan, Elizabeth, e Patricia Wratil. 2014. «In Defence of Merit - Have CEOs Become Corporate Feminists?» Comunicação apresentada na $8^{\text {th }}$ Biennial International Interdisciplinary Conference, Universidade de Keele, 24-26 de junho.

Krook, Mona Lena, e Pär Zetterberg. 2014. «Electoral quotas and political representation: Comparative perspectives.» International Political Science Review 35(1): 3-11. DOI: https: / / doi.org/10.1177/0192512113508422

Lei n. ${ }^{\circ}$ 62/2017, de 1 de Agosto - Regime da representação equilibrada entre mulheres e homens nos órgãos de administração. Disponível no endereço https://www.pgd lisboa.pt / leis / lei_mostra_articulado.php?artigo_id=2730A0013\&nid=2730\&tabela $=$ leis\&pagina $=1 \&$ ficha $=1 \&$ so_miolo $=\&$ nversao $=$ [Consultado em 11 de maio de 2021].

Lépinard, Eléonore, e Ruth Rubio-Marín. 2018. «The French parity reform.» In Transforming Gender Citizenship: The Irresistible Rise of Gender Quotas in Europe, editado por Eléonore Lépinard, e Ruth Rubio-Marín, 62-93. Cambridge, U.K.: Cambridge University Press.

Lombardo, Emanuela, e Lut Mergaert. 2013. «Gender Mainstreaming and Resistance to Gender Training: A Framework for Studying Implementation.» NORA - Nordic Journal of Feminist and Gender Research 21(4): 296-311. DOI: https: / / doi.org/10.1080 / 0803 8740.2013.851115

Meier, Petra. 2008. «A Gender Gap not Closed by Quotas: The Renegotiation of the Public Sphere.» International Feminist Journal of Politics 10(3): 329-47. DOI: https: / / doi.org/ $10.1080 / 14616740802185650$

Mensi-Klarbach, Heike, e Cathrine Seierstad. 2020. «Gender Quotas on Corporate Boards: Similarities and Differences in Quota Scenarios.» European Management Review 17(3): 615-631. DOI: https:/ / doi.org/10.1111/emre.12374

Murray, Rainbow, Mona Lena Krook, and Katherine A. R. Opello. 2012. «Why Are Gender Quotas Adopted? Parity and Party Pragmatism in France.» Political Research Quarterly 65(3): 529-543. DOI: https: / / doi.org/10.1177\%2F1065912911414590

Nogueira, M. Conceição. 2009. «Women in Positions of Power in Portugal: Contradictory Positions and Discourses.» Journal of Women, Politics and Policy 30(1): 70-88. DOI: https: / / doi.org/10.1080/15544770802367804

Santos, Maria Helena. 2010. «Género e Política: Factores explicativos das resistências à igualdade.» Tese de Doutoramento em Psicologia Social e das Organizações. Lisboa: ISCTE-IUL.

Santos, Maria Helena, e Lígia Amâncio. 2010a. «A (in)justiça relativa da acção positiva - A influência do género na controvérsia sobre as quotas baseadas no sexo.» Análise Psicológica 28(1): 43-57. DOI: https: / / doi.org/10.14417/ap.251

Santos, Maria Helena, e Lígia Amâncio. 2010b. «A competência política, a desigualdade de género e as medidas de acção positiva: Uma questão "natural" ou de "competência"?» Psicologia 24(1): 117-140. DOI: https:/ / doi.org/10.17575/rpsicol.v24i1.299

Santos, Maria Helena, e Lígia Amâncio. 2012a. «Género e política: análise sobre as resistências nos discursos e nas práticas sociais face à Lei da Paridade.» Sociologia, Problemas e Práticas 68: 79-101. Disponível no endereço https://journals.openedition.org/spp/ 696 [Consultado em 14 de junho de 2021]. 
Santos, Maria Helena, e Lígia Amâncio. 2012b. «Resistências à Igualdade de Género na Política.» ex æquo 25: 45-58. Disponível no endereço https: / / scielo.pt/pdf/aeq/n25/n25a 05.pdf [Consultado em 15 de junho de 2021].

Santos, Maria Helena, e Lígia Amâncio. 2014. «Sobreminorias em profissões marcadas pelo género: consequências e reações.» Análise Social 212: 700-726. Disponível no endereço http://analisesocial.ics.ul.pt/documentos/AS_212_d04.pdf [Consultado em 18 de junho de 2021].

Sealy, Ruth. 2010. «Changing perceptions of meritocracy in senior women's careers.» Gender in Management 25(3): 184-197. DOI: https:/ / doi.org/10.1108/17542411011036392

Seierstad, Cathrine. 2016. «Beyond the Business Case: The Need for Both Utility and Justice Rationales for Increasing the Share of Women on Boards.» Corporate Governance: An International Review 24(4): 390-405. DOI: https: / / doi.org/10.1111/ corg.12117

Seierstad, Cathrine, Gillian Warner-Søderholm, Mariateresa Torchia, e Morten Huse. 2017. «Increasing the Number of Women on Boards: The Role of Actors and Processes.» Journal of Business Ethics 141: 289-315. DOI: https://doi.org/10.1007/s10551-0152715-0

Simpson, Ruth, Anne Ross-Smith, e Patricia Lewis. 2010. «Merit, special contribution and choice: How women negotiate between sameness and difference in their organizational lives.» Gender in Management 25(3): 198-207. DOI: https:/ / doi.org/ 10.1108/1754 2411011036400

Teigen, Mari. 2000. «The affirmative action controversy.» NORA - Nordic Journal of Women's Studies 8(2): 63-77. DOI: https: / / doi.org/10.1080/08038740050167515

Terjesen, Siri, e Ruth Sealy. 2016. «Board Gender Quotas: Exploring Ethical Tensions from a Multi-Theoretical Perspective.» Business Ethics Quarterly 26(1): 23-65. DOI: https:/ / doi.org/10.1017/ beq.2016.7

Verge, Tània, e Enamuela Lombardo. 2021. «The contentious politics of policy failure: The case of corporate board gender quotas in Spain.» Public Policy and Administration 36(2): 232-251. DOI: https: / / doi.org/10.1177/0952076719852407 


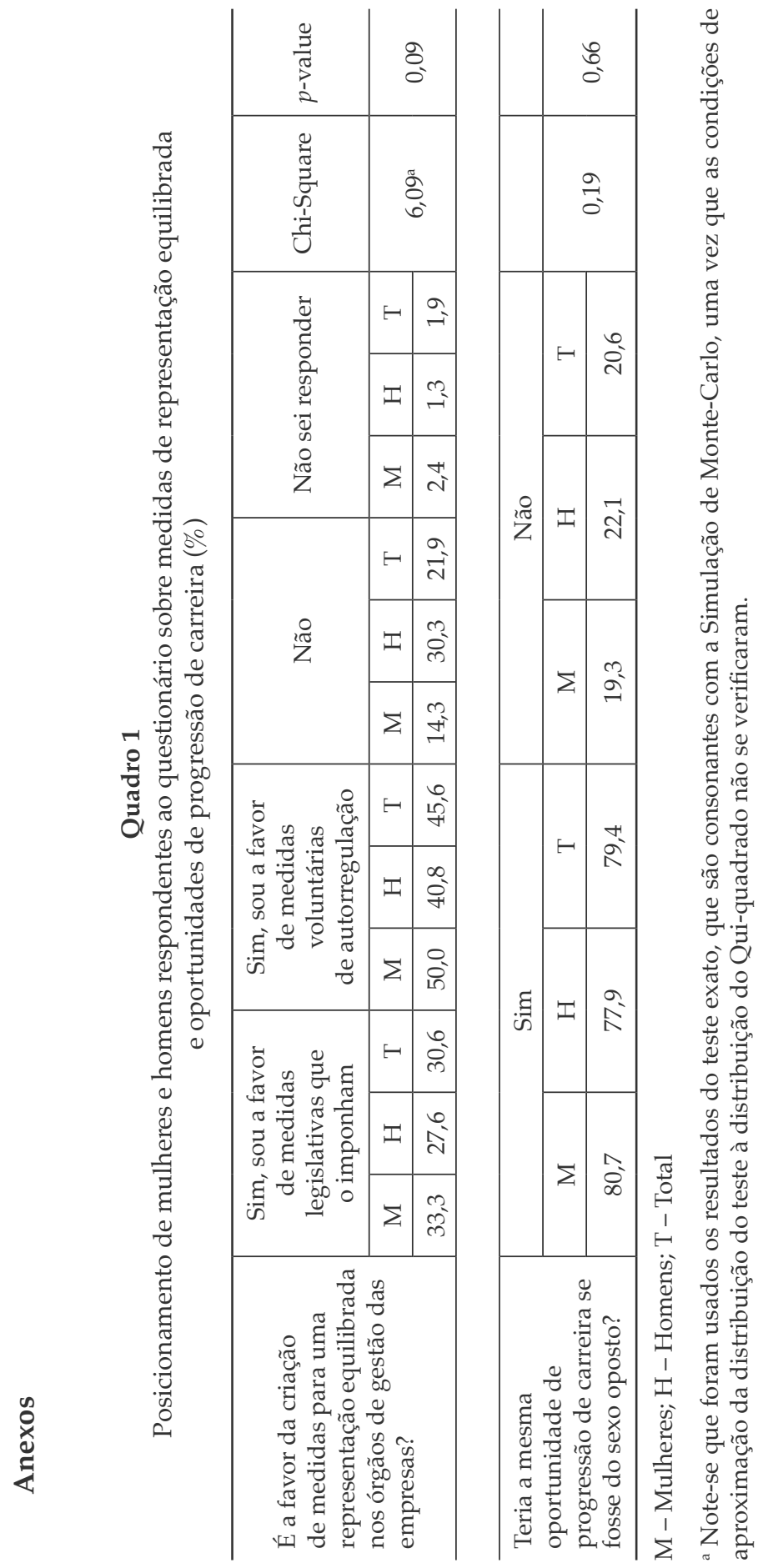


Sara Falcão Casaca, Maria João Guedes,

Susana Ramalho Marques, Nuno Paço

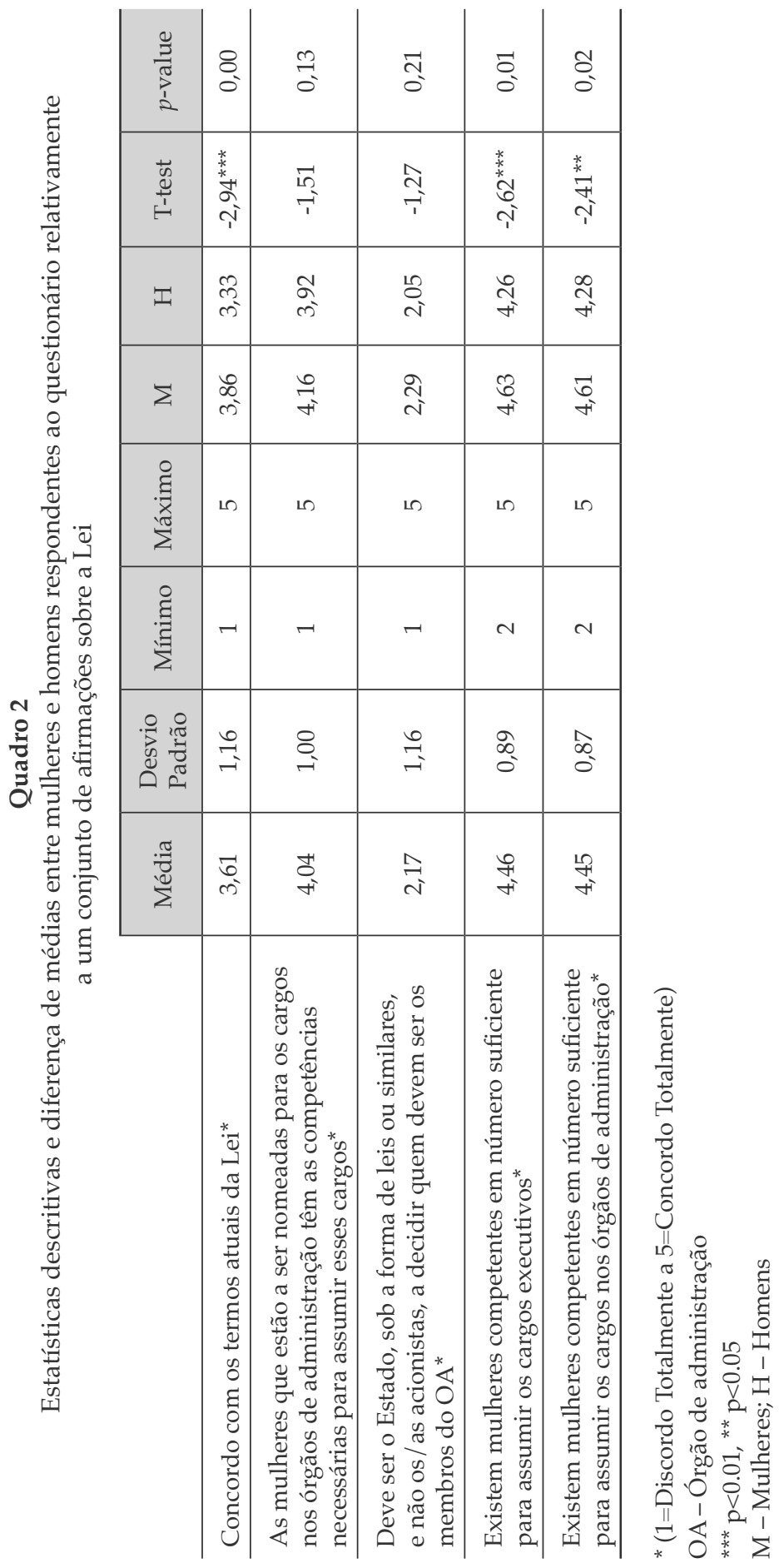


Sara Falcão Casaca. Professora Associada com Agregação do Instituto Superior de Economia e Gestão, Universidade de Lisboa, investigadora integrada do Centro de Investigação em Sociologia Económica e das Organizações (SOCIUS)/Consórcio em Ciências Sociais e Gestão (CSG), onde coordena a linha de investigação Trabalho, Emprego, Organizações e Género. É coordenadora do Programa de Doutoramento em Sociologia Económica e das Organizações.

Maria João Guedes. Professora Auxiliar com Agregação do Instituto Superior de Economia e Gestão, Universidade de Lisboa (ISEG-ULisboa) e investigadora do ADVANCE - Centro de Investigação Avançada em Gestão do ISEG, Universidade de Lisboa. Os seus interesses de investigação recaem na área da corporate governance, tendo desenvolvido trabalhos nas áreas de performance e sobrevivência das empresas através de uma perspectiva multidisciplinar, como liderança, género e elementos psicológicos.

Susana Ramalho Marques. Investigadora pós-doc no SOCIUS / CSG (ISEG-ULisboa), no Projeto «Mulheres nos Órgãos de Gestão das Empresas: uma abordagem integrada». A sua atividade de investigação tem-se centrado no multiculturalismo, minorias e a igualdade de género. Licenciada em Psicologia e mestre em Psicologia Social e das Organizações pelo ISCTE-IUL. Concluiu o doutoramento em Sociologia Económica e das Organizações no ISEG-ULisboa, com uma análise diacrónica das políticas de articulação trabalho-família em Portugal.

Nuno Paço. Bolseiro do Projeto «Mulheres nos Órgãos de Gestão das Empresas: uma abordagem integrada» (FCT e SOCIUS / CSG). É licenciado em Administração Pública pelo Instituto Superior de Ciências Sociais e Políticas, Universidade de Lisboa (ISCSPULisboa), e Mestre em Gestão de Recursos Humanos pelo Instituto Superior de Economia e Gestão, Universidade de Lisboa (ISEG-ULisboa). Desenvolveu a investigação de mestrado no âmbito do equilíbrio entre mulheres e homens nos órgãos de governo das empresas.

Artigo recebido em 03 de julho de 2021 e aceite para publicação em 29 de outubro de 2021. 